\title{
A crise política brasileira nas páginas do Humanité das denúncias de corrupção à traição dos ideais socialistas
}

\author{
Brazilian's political crisis in l'Humanité's pages: from corruption \\ denounces to the betraying of socialist's ideas
}

\author{
Fábio Henrique Pereira \\ Jornalista e professor, doutorando em Comunicação pela Universidade de Brasilia (UnB). Atualmente \\ cursa o doutorado-sanduiche na Université de Rennes 1 (França), com bolsa da Capes. \\ E-mail: fabiopereira@yahoo.com.br
}

\section{Resumo}

Neste artigo analisamos a cobertura jornalistica dispensada pelo cotidiano francês l'Humanitéà crise política no Brasil. Crise desencadeada pelas denúncias de um suposto esquema de corrupção e dos pagamentos efetuados pelo Partido dos Trabalhadores (PT) a parlamentares da base aliada ao governo (escândalo do "mensalão"). Tendo como base o conceito de enquadramento e o modelo das controvérsias interpretativas, realizamos uma análise qualitativa do conteúdo publicado pelo Humanité entre junho e novembro de 2005. Procuramos analisar as escolhas interpretativas feitas pelos jornalistas na seleção das fontes e no tratamento das informações coletadas. Essa análise permitiu compreender como o jornal construiu uma imagem sobre a crise política brasileira para o público.

'No vocabulário político brasileiro, o "mensalão" se refere a um suposto esquema de pagamentos mensais feitos pelo Partido dos Trabalhadores a deputados do Partido Progressista (PP) e do Partido Liberal (PL), no valor de $\mathrm{R} \$ 30$ mil. 0 escândalo teve início após denúncias do deputado Roberto Jefferson (na época pertencente ao Partido Trabalhista Brasileiro) ao jornal Folha de S. Paulo. Embora não haja provas concretas sobre a existência do "mensalão", as denúncias de Jefferson, mais tarde corroboradas por outras testemunhas, provocaram uma crise política no governo, o que incluiu a formação de uma Comissão Parlamentar de Inquérito (CPI), a renúncia e a cassação de vários deputados da base aliada, dentre eles o ex-braço direito do presidente, José Dirceu. No interior do Partido dos Trabalhadores, os escândalos resultaram no afastamento do presidente José Genoíno e na convocação de novas eleições para a direção do partido. Sobre 0 assunto, ver "Especial Folha OnLine - CPI do mensalão em: http:/ /www1.folha.uol.com.br/folha/ especial/2005/cpidomensalao/

Palavras-chave: jornalismo político, imprensa francesa, enquadramento, controvérsias interpretativas.

Aos olhos da imprensa francesa, a eleição do presidente Luiz Inácio Lula foi marcada por uma forte carga simbólica. A história de um exmetalúrgico que chega ao poder na maior nação sul-americana despertou uma mistura de fascínio e admiração na opinião pública. No caso da imprensa de gauche, essa simpatia explica-se também pelas esperanças depositadas sobre o governo do Partido dos Trabalhadores (PT) no processo de renovação dos ideais de esquerda, desgastados pelo fim do socialismo real, pela crise da social democracia européia e pela emergência do pensamento único neoliberal.

Uma imagem que dificilmente se mantém intacta a partir da crise política que se instaura no Brasil, em decorrência das denúncias de corrupção. No caso do nosso objeto de estudo, o cotidiano francês l'Humanité, essa nova situação impõe um verdadeiro dilema. Por um lado, condenar o governo do Partido dos Trabalhadores significa adotar os mesmos argumentos de uma oposição burguesa e conversadora, o que prejudicaria as pretensões de uma hegemonia política da esquerda internacional. Por outro lado, assumir a defesa do PT poderia ser visto como uma posição excessivamente pragmática do jornal, no sentido de colocar a conquista e a manutenção do poder acima da utopia socialista e das esperanças depositadas em torno da eleição de Lula.

Nesse sentido, propomo-nos a tentar compreender como o Humanité buscou solucionar esse dilema, a partir de um análise da cobertura realizada pelo jornal sobre a crise política no governo petista, desencadeada a partir do escândalo do "mensalão" .

Para a realiżação deste estudo, coletamos, entre os meses de junho e novembro de 2005 , todo material publicado pelo Humanité referente à crise no Brasil. Numa segunda etapa, 
descartamos notas e matérias em que o assunto era tratado de forma superficial. Após o tratamento desse material, constituímos um corpus de 08 matérias publicadas ${ }^{2}$, que submetemos a uma análise qualitativa de conteúdo, operacionalizada a partir do referencial teórico-metodológico adotado.

A notícia como uma construção social da realidade

Nosso referencial situa-se na perspectiva construcionista dos estudos sobre jornalismo. Ou seja, refutamos a noção de notícia como um "espelho da realidade" ou como resultado de mecanismos de distorção voluntária dos acontecimentos (Traquina, 2001) ${ }^{3}$. No nosso entendimento, a produção jornalística deve ser compreendida como processo interpretativo que constrói uma realidade socialmente compartilhada, mediante a "rotinização da própria dinâmica social, estabilizando-a em a contecimentos-tipo, comportamentos previsíveis e erupções controladas" (Correia, 1995: 02).

Mais do que retratar um evento, o trabalho jornalístico se destina a produzir marcos interpretativos, mapas de significado capazes de "fazerem sentido", de se relacionarem com as identificações sociais e culturais do público ${ }^{4}$. "A identificação social, classificação e contextualização de acontecimentos noticiosos em termos desses quadros de referência de fundo constitui o processo fundamental através do qual os media tornam o mundo a que eles fazem referência inelegível a leitores e espectadores" (Hall et all, 1993: 226).

Um segundo pressuposto dessa perspectiva busca compreender a

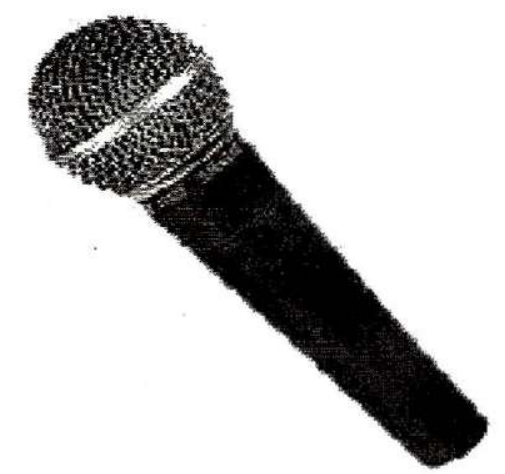

produção jornalística a partir de um processo de interação social entre jornalistas, fontes de informação e sociedade (Traquina, 2001). Anotícia resulta de uma combinação entre vários níveis de influência, que extrapolam a ação pessoal do jornalista (Sousa, 2000). Na verdade, a autonomia do produtor é sempre limitada pelas rotinas profissionais, pelos constrangimentos do tempo, pelos valores-notícia e pela rede de interações sociais partilhada com indivíduos e instituições dentro e fora das redações ${ }^{5}$.

Assim, tão importantes quanto as rotinas profissionais dos jornalistas são as ações mobilizadas pelas fontes de informação, no sentido de influenciar a agenda jornalística (Schlensiger, 1992; Molotch e Lester, 1993; Traquina, 2001; Motta, 2004) e o papel desempenhado pelos constrangimentos organizacionais na construção da notícia (Sousa, 2000). Por isso, a necessidade de conhecer melhor a posição do Humanité no cenário mediático francês.

\section{L'Humanité entre o partido e o público}

Para situarmos melhor o status atual do Humanité é preciso compreender como evolui historicamente sua posição na imprensa francesa, a partir de suas relações com o Partido Comunista Francês (PCF). Fundado em 1904, por Jean Jaurès, como um jornal socialista, mas sem vinculação
${ }^{2} O$ s arquivos estão disponíveis online em www.humanite.fr.

${ }^{3} \mathrm{Na}$ verdade, Traquina denomina de modelo construcionista diferentes estudos que compartilham o mesmo princípio do jornalismo como construção da realidade.

4 Essa noção de atalhos interpretativos já havia sido sugerida, em 1922, pelo jornalista norte-americano Walter Lipmann. A teoria de Lipmann sugere que, diante da complexidade do mundo social, os individuos se proponham a criar pseudo-ambientes, mapas ou atalhos, que seriam utilizados na compreensão da realidade. Esses mapas governariam nossas ações sobre 0 ambiente real. A imprensa participaria desse processo de construção de atalhos, embora essa atuação prejudique o sistema democrático como um todo, na medida em que a "analysis of news and economic basis of journalism seems to show that the newspapers necessaraly and inevitable reflect, and therefore, in greater or lesser mesure, intensify, the defective organization of public opinion." LIPMANN, Walter. The Worl outside and the pictures in our heads. In Public Opinon. New York, Free Press, 1922, p. 32.

${ }^{5}$ Sobre o assunto, ver TRAQUINA, Nelson (org.) Jornalismo: Questões, teorias, estórias. Lisboa :Vega, 1993; SOUSA, Jorge Pedro. As notícias e os seus efeitos. Coimbra : Minerva, 2000; TRAQUINA, Nelson. O Estudo do Jornalismo no Século XX. São Leopoldo: Unisinos, 2001 : entre outros. 
${ }^{6}$ Livre tradução de: "défendre, commenter, éclairer leur vision du monde, mais aussi conduire des campagnes d'information, soutenirles luttes sindicales et fournir au prolétariat les outils nécessaires pour combattre le patronat et les puissances d'argent".

${ }^{7}$ Livre tradução de: "le lecteur de l'Humanité est aussi un lecteur comme un autre. II ne se nourrit pas seulement de slogans ou d'analyse politique: il veut une autre information, du sport, du récit ou du fait divers; fait divers que rejette l'equipe du journal, mais qu'elle est bien obligée de couvrir, comme les autres journaux, car le spetaculaire fait vendres".

${ }^{8}$ Livre tradução de : "Il s'agit d'acquérir une légitimité externe (auprès des lecteurs) et interne (auprés des pairs) qui passe notamment par le distension du lieu au PCF". partidária, o Humanité tinha como objetivo "defender, comentar, esclarecer sua visão de mundo, mas também conduzir campanhas de informação, sustentar as lutas sindicais e fornecer ao proletariado as ferramentas necessárias para combater o patronato e o poder do capital $^{6 "}$ (Delporte, 2004: 11).

À inauguração do jornal, seguese uma crise financeira, provocada pela baixa vendagem. Como afirma Delporte, no início do século XX, a imprensa popular, informativa e "burguesa" na França despertava maior interesse da classe operária do que os jornais politizados de gauche. Assim, em 1918, enquanto o Humanité ainda patinava na faixa de 60,70 mil exemplares, cotidianos como Le Petit Journal e Le Petit Parisien superavam a faixa dos 1,5 milhão de jornais vendidos.

Os problemas financeiros levam à dissolução societária do Humanité em 1907. A partir daí, como explica Alexandre Courban (2004), as relações entre o jornal e os comunistas evoluem de uma independência a uma identificaçã̃o e, por fim, ao controle direto sobre a redação, em 1923. Essa etapa coincide com a cisão do Partido Socialista e a criação do PCF, que passa a controlar o Humanité, como "organe central du Parti Communiste".

O sucesso do jornal durante a Resistência - suas vendas passam de 300 mil em 1938 a 423 mil em 1945 - leva os dirigentes do Humanité a insistirem numa linha editorial mais politizada. Enquanto isso, as vendas declinam e o jornal torna-se cada vez mais dependente dos anúncios pagos pela União Soviética e pelas demais repúblicas socialistas. Na verdade, a influência do partido leva a uma decalagem entre o cotidiano e os seus leitores. O declínio nas vendas do jornal não só evidencia esse descolamento, como também os limites e contradições de um jornal "revolucionário", submetido às imposições do sistema capitalista (Euno, 2004). Como explica Delporte (2004: 15), "o leitor do Humanité é um leitor como qualquer outro. Ele não pode se abastecer apenas de slogans ou de análises políticas: ele quer uma outra informação, de esporte, de relato, de fait divers; fait divers que é rejeitado pela equipe do jornal; contudo, ela se vê obrigada a cobri-lo, como os demais jornais, pois o espetacular vende ${ }^{7}$ ".

Essa contradição se agrava a partir da década de 1990 , com o crescimento do déficit financeiro do jornal e o declínio da imprensa de opinião em toda a França. De acordo com Eugénie Saitta (2004), esse contexto leva a uma mudança no projeto editorial do Humanité, a partir de 1999. Em primeiro lugar, por um movimento progressivo de desvinculação do status de "órgão do partido". Uma segunda mudança se opera na profissionalização dos critérios de seleção dos jornalistas, que deixam de ser necessariamente ligados ao PCF. Por fim, ocorre uma renovação no projeto gráfico e a adoção de práticas predominantes na imprensa tradicional: tribunas para contribuições externas, produção de um jornalismo investigativo e de aprofundamento. "Trata-se de adquirir uma legitimidade externa (junto aos leitores) e interna (junto aos pares) que passa notadamente por uma distensão dos laços com o PCF" (Saitta, 2004: 230).

A despeito dessas mudanças, o jornal ainda se mantém ligado ao Partido Comunista. Mesmo transformando a estrutura societária, com a introdução de acionistas externos, $40,71 \%$ do Humanité ainda está nas mãos de antigos partidários (Euno, 2004). Para alguns 
empregados, ele ainda é visto como um veículo do Partido, que ainda indica o nome do diretor do quotidiano e do diretor de redação.

Essa situação contraditória - de uma imprensa partisan que busca se modernizar - serve como pano de fundo para a nossa pesquisa sobre a cobertura da crise petista nas páginas do Humanité.

\section{Operacionalizando a pesquisa: enquadramento e controvérsias} interpretativas

$\mathrm{Na}$ perspectiva construcionista do jornalismo, a noção de enquadramento (framming) oferece um quadro conceitual bastante apropriado à nossa proposta de trabalho. Esquemas de interpretação do mundo, os enquadramentos constroem princípios de organização que estruturam os eventos do cotidiano e o nosso engajamento subjetivo (Goffman, 1991). Segundo Rieffel (2005: 251), adotar essa perspectiva "implica, em efeito, que os atores sociais sejam capazes de identificar e classificar os fenômenos, de se situarem em meio à selva de eventos que os envolvem e de traduzir suas aspirações sob a forma de um discurso apropriado $9 "$.

A mídia teria papel importante na difusão de quadros hegemônicos, na medida em que privilegia determinados frammings interpretativos e marginaliza ou exclui pontos de vista alternativos (Porto 2002). Na medida em que o discurso jornalístico se constrói em torno de um referencial social e cultural comum, esses enquadramentos teriam papel importante na produção de um consenso compartilhado. "Assim, quando os acontecimentos são 'delineados' pelos media em enquadramentos de significado e interpretação, supõe-se que todos nós

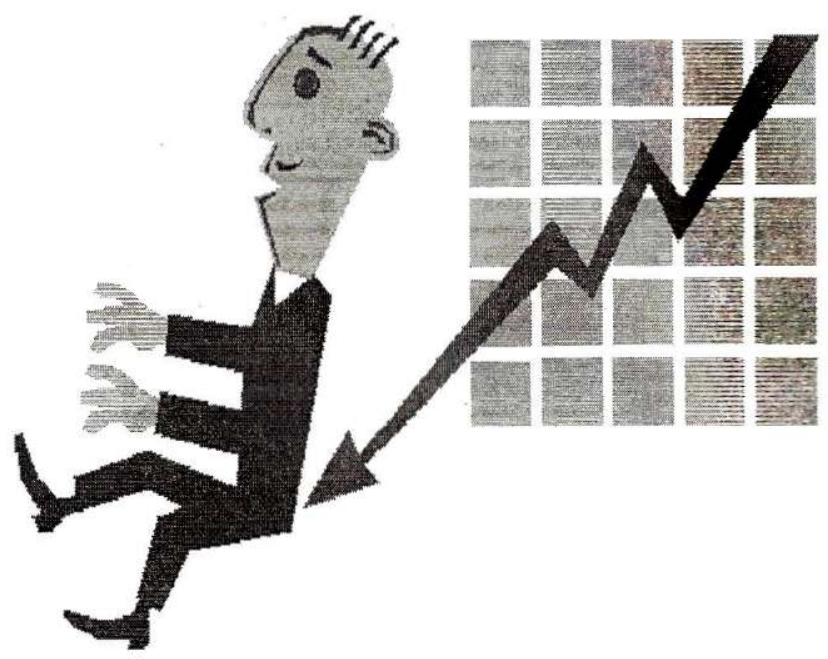

possuímos e sabemos igualmente como utilizar esses enquadramentos, que eles são extraídos fundamentalmente das mesmas estruturas de compreensão para todos os grupos sociais e públicos" (Hall et all, 1993: 227).

Para operacionalizar esse referencial teórico, adotaremos o modelo das "controvérsias interpretativas" desenvolvido por Mauro Porto $(2002,2004)^{10}$. Esse modelo enfatiza o papel dos diversos atores sociais externos (governo, partidos políticos, movimentos sociais, sindicatos e associações profissionais) na mobilização de enquadramentos interpretativos que podem ou não ser incorporados pela mídia. Sua análise busca identificar o predomínio de certos quadros interpretativos na mídia, conforme a seguinte classificação:

1. Restrito: quando apenas um enquadramento interpretativo sobre o tema é apresentado na noticia;

2. Plural-fechado: quando mais de um enquadramento interpretativo sobre o tema ou evento são apresentados pela notícia, mas são organizados em uma hierarquia na qual uma das interpretações é preferida sobre as demais ou apresentada como superior ou mais correta
${ }^{9}$ Livre tradução de : « implique en effet que les acteurs sociaux soient à même d'identifier et de classer les phénomènes, de se repérer dans la jungle des événements qui les entourent et de leurs aspirations sous forme d'un discours approprié "

${ }^{10}$ É possivel encontrar referências a esse modelo, desenvolvido durante pesquisa de doutorado, em outros trabalhos do autor. Ver, por exemplo, PORTO, Mauro P. Framing the world of politics: how governmental sources shape the production and the reception of TV news in Brazil, trabalho apresentado à XXIII. Conferência Anual da International Association for Media and Communication Research (IAMCR), Barcelona, julho, 2002; e PORTO, Mauro P. Mauro P. Porto, Making sense of politics: TV news and the interpretation of politics in Brazil, trabalho apresentado à XXII Conferência Internacional da Latin American Studies Association (LASA) , Miami, Estados Unidos, de 16 a 18 de março de 2000. 
3. Plural aberto: quando mais de um enquadramento interpretativo sobre o tema ou relato são apresentados pela notícia, mas tratados de forma mais indeterminada, sem que nenhuma interpretação seja privilegiada ou apresentada como a mais correta;

4. Episódico: quando nenhum enquadramento interpretativo é apresentado pela noticia, que se limita a relatar algum tema ou evento (Porto, 2002: 05).

Essa classificação resulta da forma como o jornalista - dentro de suas rotinas produtivas, dos constrangimentos organizacionais e da interação com as fontes - organiza hierarquicamente as diferentes subjetividades na construção do discurso noticioso. No caso do modelo "tradicional" das controvérsias interpretativas, essa análise se operacionaliza pelo estudo das "sonoras" que compõem as reportagens de um telejornal. Nesta pesquisa, faremos uma adaptação dessa proposta, a partir de uma análise das posições atribuídas às fontes (com ou sem "aspas") utilizadas pelos jornalistas durante a montagem do texto.

A escolha das fontes e a produção de quadros interpretativos: uma primeira abordagem do corpus

Durante o processo de construção da notícia, alguns atores têm acesso privilegiado à cobertura jornalística, em decorrência de sua posição social como fontes "autorizadas" (Hall et all, 1993). Assim, ocupariam o papel de "definidores primários" (primary definers) no estabelecimento de quadros interpretativos sobre a realidade. Para Hall, esses definidores se originariam, sobretudo, do aparato de controle político e social. Contudo, durante nossa análise sobre os primary definers presentes na cobertura realizada pelo Humanité, verificamos a existência de atores provenientes, sobretudo, da esquerda política brasileira, conforme mostra a tabela 1:

\begin{tabular}{|c|c|c|c|c|c|}
\hline & Data & Titulo & Editoria & Autor & Fontes utilizadas \\
\hline Al & $20 / 06$ & Ça Tangne autour de Luks & Monde & $\begin{array}{l}\text { Bernard } \\
\text { Duraud }\end{array}$ & $\begin{array}{l}\text { Roberto Jéfferson (ex-deputado petebista, } \\
\text { cassado), José Genoino (ex-presidente do } \\
\text { PT), Jose Dirceu (ex-presidente do PT, ex- } \\
\text { Ministro da Casa Civil e deputado cassado) }\end{array}$ \\
\hline A2 & $12 / 07$ & Lula, mise à Péprouve & Monde & B. Duraud & sem fonte \\
\hline A3 & $13 / 07$ & Luka se ressource à Paris & Monde & B. Duraud & sem fonte \\
\hline A4 & $15 / 07$ & $\begin{array}{l}\text { L'homme du jour Luiz } \\
\text { Inácio Lula da Silva }\end{array}$ & Ripostes & Cyrille Poy & $\begin{array}{l}\text { Lula, Movimento dos Trabalhadores sem } \\
\text { Terra (MST), Jorge Ben Jor (cantor e } \\
\text { compositor) }\end{array}$ \\
\hline A5 & $12 / 08$ & $\begin{array}{l}\text { Lula épargné par le } \\
\text { scandale }\end{array}$ & Monde & $\begin{array}{l}\text { David } \\
\text { Samson }\end{array}$ & sem fonte \\
\hline A6 & $31 / 08$ & $\begin{array}{l}\text { Impossible refondation du } \\
\text { Parti des travailleurs? }\end{array}$ & Monde & D. Samson & $\begin{array}{l}\text { Tarso Genro (ex-ministro da Educacăão) } \\
\text { exerceu, durante certo periodo, o cargo de } \\
\text { presidente do PT, Raul Pont (ex-prefeito de } \\
\text { Porto Alegre), Lula, Fernando Hentique } \\
\text { Cardoso (ex-presidente da República) e } \\
\text { MST. }\end{array}$ \\
\hline A7 & $12 / 10$ & $\begin{array}{l}\text { Brésil Remous au sein du } \\
\text { Parti des travailleurs }\end{array}$ & Monde & - & Raul Pont, "Outros Candidatos"* \\
\hline A8 & $05 / 11$ & Paroles d'mis troublés & Monde & B. Duraud & $\begin{array}{l}\text { Oded Grajew (um dos organizadores do } \\
\text { FSM, Jose de Filippi Junior (prefeito de } \\
\text { Diadema), Kjeld Jacobsen (ex-dirigente da } \\
\text { CUT), }\end{array}$ \\
\hline
\end{tabular}

Tabela 1: Fontes utilizadas pelo jornalista na construção de composição do seu "quadro interpretativo". As declarações que não faziam menção à crise no governo Lula foram excluídas da análise.

*Refere-se a um grupo de candidatos à presidência do PT que faziam oposição à corrente Articulação, majoritária dentro do PT e da qual fazem parte o presidente Lula, o ex-Ministro José Dirceu e o atual presidente do partido Ricardo Berzoini. 
Essa sobrevalorização das fontes "não-autorizadas" evidencia os limites de se pensar a produção midiática em termos de sua subserviência ao poder, como sugere o modelo proposto por Hall. $\mathrm{Na}$ verdade, a maior parte das fontes utilizadas encontram-se distantes das esferas do governo petista, na medida em que ocupam uma posição secundária dentro da esquerda brasileira. São fontes ligadas aos movimentos sociais (MST, Oded Grajew), sindicais (Kjeld Jacobsen) e grupos políticos considerados minoritários no interior Partido dos Trabalhadores (Tarso Genro, Raul Pont, José de Filippi Junior).

A ênfase dada a esses personagens explica-se, em parte, pelos constrangimentos de tempo subjacentes às rotinas profissionais dos jornalistas (Sousa, 2000; Hall, 1993; Schlensiger, 1993), que os induzem a recorrer a fontes mais acessíveis - no caso do Humanité, antigos companheiros comunistas. Uma segunda explicação estaria na seleção de atores que correspondem aos marcos interpretativos condizentes

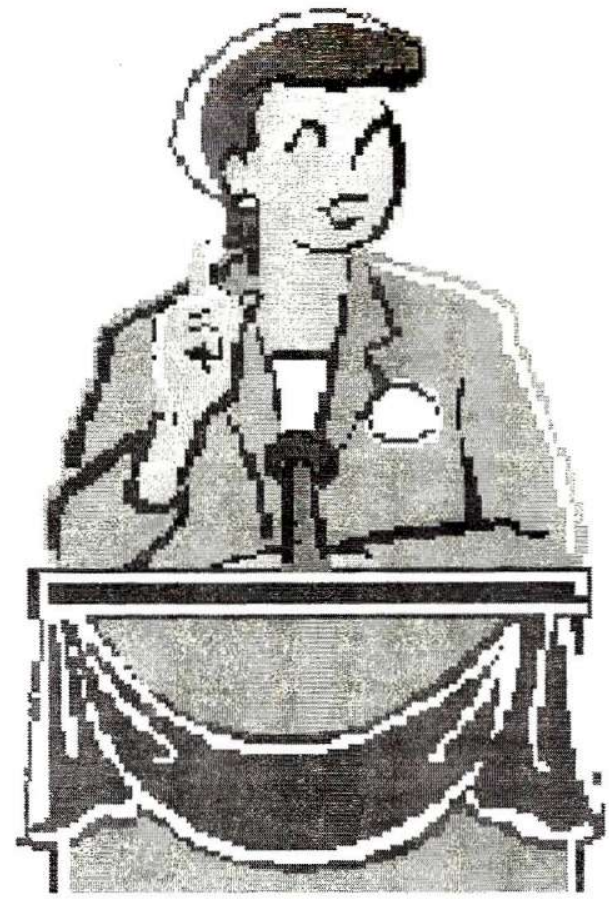

com o discurso veiculado pelo jornal. $\mathrm{Na}$ verdade, ao analisarmos os modelos de enquadramento veiculados, sob a perspectiva das controvérsias interpretativas, percebemos claramente a construção de um marco interpretativo hegemônico, ao identificarmos a ausência de matérias organizadas a partir do modelo pluralaberto (tabela 02):

\begin{tabular}{|l|l|}
\hline Matéria & Enquadrame nto \\
\hline A1 & Plural Fechado \\
\hline A2 & Episódico \\
\hline A3 & Episódico \\
\hline A4 & Plural féchado \\
\hline A5 & Episódico \\
\hline A6 & Plural Fechado \\
\hline A7 & Restrito \\
\hline A8 & Restrito \\
\hline
\end{tabular}

Tabela 2: Classificação das reportagens publicadas no Humanité, segundo o enquadramento adotado em relação ao governo Lula (modelo das "controvérsias interpretativas").

Aprofundando a análise: as representações veiculadas pelo Humanité

Essa primeira aproximação com objeto nos permitiu identificar como a cobertura se estrutura a partir das escolhas feitas pelos jornalistas em torno dos enquadramentos adotados e das fontes de informação utilizadas. Essa abordagem, contudo, não nos 


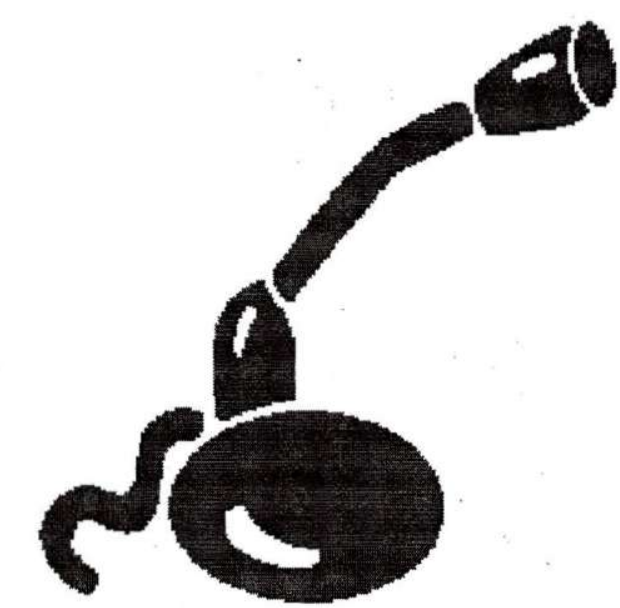

"Livre tradução de : Et Jefferson, un allié de Lula au sein de la coalition gouvernementale, avait lancé sur le ton de la menace : " José Dirceu, si vous ne sortez pas de là, vous allez faire d'un homme bon [Lula] un accusé ".

${ }^{12}$ Livre tradução de: "Cependant, jusqu'ici tout le monde a pris soin d'innocenter Lula, tandis que I' 'opération peigne fin' à laquelle ont été soumis ses comptes bancaires et son agenda n'a rien donné. Jefferson a dit que les pots-de-vin avaient cessé dès que Lula en a été informé en janvier 2005. (...) Aussi Lula, qui reste populaire, continue-t-il à gouverner et à préparer l'élection présidentielle de 2006.

13 Livre tradução de: "Le Mouvement des sans-terre s'est dit, quant à lui, " perplexe " devant la reprise par le PT d'une " pratique traditionnelle de la droite " et a réaffirmé son autonomie par rapport aux partis et à l'État, soulignant l'importance du mouvement social et la nécessité de construire un " projet " collectif pour le Brésil.

${ }^{14}$ Face à la corruption, Jacobsen semble regretter une réforme politique qui n'a pas eu lieu. C'était là la seule façon de mettre fin à des pratiques "illégales " séculaires ayant cours pratiquement depuis la colonisation. Lula dans une certaine mesure risque de payer comptant " des alliances contre nature " permite concluir se essas escolhas resultaram numa cobertura favorável ao presidente Lula e ao PT. Nesse sentido, parece importante partir para uma análise mais aprofundada do nosso corpus, de forma a compreender melhor o conteúdo dos quadros apresentados.

\section{Culpados e inocentes}

Seja nas escolhas das fontes, seja no discurso do repórter, a cobertura do Humanité busca interpretar os eventos da crise, atribuindo responsabilidades a diferentes atores sociais. Assim, o presidente Lula será visto como um personagem alheio à crise, sem uma responsabilidade direta com os escândalos de corrupção:

A1: E Jefferson, um aliado de Lula no seio da coalizão governamental, havia lançado [a denúncia] em tom de ameaça: "José Dirceu, se você não sair dai, você vai fazer de um bom homem [Lula] um acusado" ".

A5: No entanto, até o momento, todos se preocupam em inocentar Lula, ao passo que a "operação pente fino", aquela a que foram submetidas suas contas bancárias e sua agenda, não resultou em nada. Jefferson disse que o esquema de propina terminou assim que Lula foi informado, em janeiro de 2005. Assim, Lula, que segue popular, continua a governar $e$ a preparar a eleição presidencial de $2005^{12}$.

Com as falas das fontes à esquerda do governo Lula, o Humanité busca construir uma imagem de degeneração de certos quadros do PT, que, estando no poder, passam a adotar práticas de administração essencialmente "burguesas". Assim, percebemos uma ênfase na necessidade de refundar o partido em meio à crise, refutando as alianças feitas com facções políticas conservadoras e propondo uma alternativa "socialista" aos problemas de corrupção:

A6: O movimento dos sem-terra se diz "perplexo" diante da retomada pelo $P T$ de uma "prática" tradicional da direita" e a reafirmar a sua autonomia em relação aos Partidos e ao Estado, sublinhando a importância do movimento social $e$ a necessidade de construir um "projeto" coletivo para o Brasill1.

A8: Face à corrupção, Jacobsen parece lamentar uma reforma política que não teve lugar. Esta era a única maneira de por fim às práticas 'ilegais' seculares que vêm sendo feitas desde a colonização. Lula, de certa forma, pode pagar a conta 'pelas alianças contra a natureza'. A falta de fidelidade e a fome pelo poder complicam seriamente o jogo politico ${ }^{14}$.

A partir daí, a crítica se estende à política econômica adotada pelo governo Lula, de forma a associar os escândalos de corrupção ao abandono dos ideais socialistas pelo PT. Verifica-se esse tipo construção tanto na fala das fontes selecionadas como pelo discurso autoral do jornalista: 
A4: Mas, para além dos escândalos, é a politica social e econômica que é largamente criticada, notadamente pelos partidários do Movimento dos Sem Terra e os pobres que contribuiram amplamente à sua eleição [de Lula]. Hoje, eles fazem parte dos marginalizados pelo governo de Lula, enquanto os meios abastados se mostram mais satisfeitos pela boa saúde da economia brasileira ${ }^{I 5}$.

A4: "É uma honra ter um presidente operário que conseguiu tirar as elites do poder", declarava quarta-feira à noite o cantor Jorge Ben Jorge. Ele tem razão, mas se trata atualmente de alimentar o povo ${ }^{16}$.

A7: $O$ debate interno [do PT, por ocasião das eleições do novo presidente] não se coloca apenas sob a questão ética do partido, mas também sobre a politica de austeridade orçamentária conduzida pelo governo Lula e as altas taxas de juros praticadas pelo banco central $^{17}$.

A7: "Eu não compreendo como essa politica oriunda da escola neoliberal pode ser defendida por nosso partido e apresentada como modelo ideal para a economia do pais", declarou Raul Pont, o candidato da ala esquerda do $P T^{18}$.

Dentro dessa preocupação, percebe-se uma tentativa de separar a crise na administração petista de um projeto socialista de governo. Para resguardar a utopia de gauche das decepções da realidade política, o Humanité busca associar os escândalos de corrupção à gestão neoliberal da economia pelo PT. Essa associação pretende promover uma espécie de pacificação com os leitores, à medida que inverte a relação de inocentes e culpados no contexto da

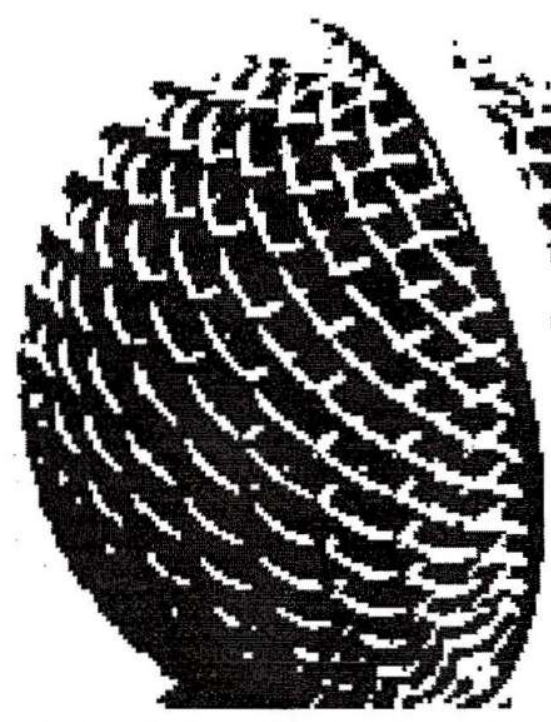

crise brasileira, atribuindo às práticas tradicionais da direita e à política oriunda da escola neoliberal a responsabilidade pela crise política. Assim, o Humanité fornece ao público um quadro explicativo que lhe permite continuar acreditando no socialismo, a despeito do "fracasso" da administração petista no Brasil. Foi a forma encontrada pelo jornal para resolver o dilema apresentado pela crise no governo Lula.

\section{Conclusão}

$\mathrm{O}$ presente artigo dedicou-se a uma breve análise da cobertura da crise política no governo Lula, pelo cotidiano francês l'Humanité. Buscamos fundamentar nossa compreensão sobre a produção de notícias a partir de uma abordagem construcionista da prática jornalística. Amparados nesse arcabouço, foi possível estabelecer as seguintes conclusões:

1) Longe de retratar uma realidade objetiva, o Humanité buscou fornecer aos seus leitores quadros interpretativos sobre a crise política no Brasil. Funcionou, portanto, como agente na construção de uma realidade social que pode ou não ser aceita pelo leitor;

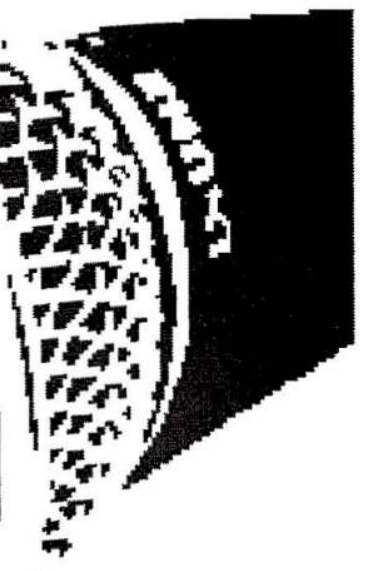

15 Livre tradução de: « Mais, au-delà des scandales, c'est sa politique sociale et économique qui est largement critiquée, notamment par les partisans du Mouvement des sans-terre et les pauvres qui ont largement contribué à son élection. Aujourd'hui, ils font partie des déçus de la présidence Lula, quand les milieux aisés se montrent eux plutôt satisfait, par la bonne santé de l'économie brésilienne ».

${ }^{16}$ Livre tradução de: «C'est un honneur d'avoir un président ouvrier qui a réussi à renverser les élites ", déclarait mercredi soir le chanteur Jorge Ben Jor. Il a raison, mais il s'agit maintenant de nourrir le peuple.

17 Livre tradução de: « Le débat interne ne porte pas seulement sur l'éthique du parti, mais aussi sur la politique d'austérité budgétaire menée par le gouvernement Lula et les taux d'intérêts élevés pratiqués par la banque central »e.

18 « Je ne comprends pas comment cette politique issue de l'école néolibérale peut être défendue par notre parti et présentée comme modèle idéal pour l'économie du pays "), a déclaré Raul Pont, le candidat de l'aile gauche du PT. 


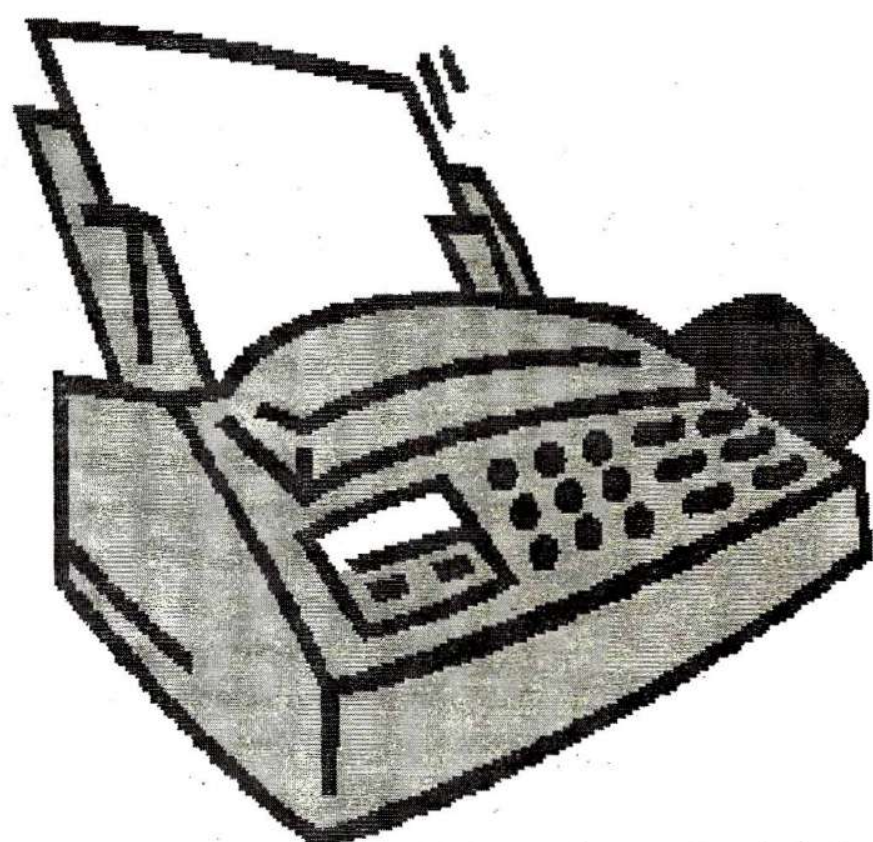

2) A angulação adotada pelo jornal deriva de uma interação entre as escolhas pessoais dos jornalistas, o discurso veiculado pelas fontes e a linha editorial adotada pelo Humanité no contexto da imprensa francesa;

3) Nossa primeira abordagem sobre os enquadramentos utilizados no decorrer da cobertura mostrou uma predominância de quadros restritos ou fechados, construídos a partir de fontes majoritariamente provenientes da esquerda política;

4) Essa seleção de fontes à esquerda não implicou numa cobertura favorável ao governo petista. Pelo contrário, buscou resguardar o socialismo, como ideologia universalizante, da crise política no Brasil. Estratégia que se constrói pela construção de quadro interpretativo em que se busca desvincular o governo Lula da "verdadeira esquerda", tachando-o como incapaz de corresponder às expectativas criadas em torno da sua administração. Para o Humanité, a crise política no
Brasil representa um "castigo" recebido pelo governo por essa "traição". A "Refundação do partido dos trabalhadores", título de uma das reportagens do Humanité, não é apenas uma reformulação ética, mas, sobretudo, ideológica.

Assim, o Humanité resolve seu dilema retomando uma antiga noção gramsciniana, que situa o verdadeiro projeto socialista como processo de "catarse política" e busca superar os interesses corporativos do cotidiano político - o interesse do PT em se manter no poder, por exemplo - em direção a uma consciência universal e universalizante.

\section{Abstract}

In this paper, we analyze news covering of Brazilian's political crisis in French newspaper l'Humanité. This crisis results from denounces about a supposed corruption schema. It's also a consequence of payings made by Workers Party (PT) to government members of parliament ("mensalão" scandal). By using framing concept and interpretative controversies model, we realized a qualitative content analysis about l'Humanité from June to November 2005. We looked for journalists' interpretative choices on source selection and information editing. This study did possible understand how newspaper constructed an image of political crisis in French public.

Keywords: political journalism, French press, framming, interpretative controversies model.

\section{Referência}

CORREIA, João Carlos (1995). O Poder do Jornalismo e a Mediatização do Espaço Público. Biblioteca on-line das Ciências da Comunicação, acessado em: 14/04/2003. <http:// bocc.ubi.pt/pag/_texto.php3?html2=jcorreiapoder-jornalismo.html.

COURBON, Alexandre (2004). 'L'Humanité, du 
Socialisme au Communisme'. In: DELPORTE, Christian; PENNETIER, Claude; SIRINELLI, JeanFrançois et WILIKOW, Serge. L'Humanité de Jaurès à nous jours. Paris, Nouveau Monde Éditions, pp. 59-73.

COUTINHO, Carlos Nelson (1989). Gramsci: um estudo sobre seu pensamento político. Rio de Janeiro, Campus.

DELPORTE, Christian (2004). 'L'Humanité, un siècle d 'existence'. In: DELPORTE, Christian; PENNETIER, Claude; SIRINELLI, Jean-François et WILIKOW, Serge. L'Humanité de Jaurès à nous jours. Paris, Nouveau Monde Éditions, pp. 11 18.

EUNO, Patrick (2004). 'L'Humanité, une entreprise politique'. In: DELPORTE, Christian; PENNETIER, Claude; SIRINELLI, Jean-François et WILIKOW, Serge. L'Humanité de Jaurès à nous jours. Paris, Nouveau Monde Éditions, pp. 199210.

GOFFMAN, Erwing (1991). Les cadres de l'expérience. Paris : Les Editions de Minuit. HALL, Stuart; CHRITCHER, Chas; JEFFERSON, Tony; CLARKE, John; ROBERTS, Brian (1993). "A produção social das notícias: o mugging nos media". In: Traquina, Nelson. (org.). Jornalismo: questões, teorias e "estórias". Lisboa: Vega, pp. 224-248.

MOLOTCH, Harvey e LESTER Marilyn (1993). 'As notícias como procedimento intencional: acerca do uso estratégico dos acontecimentos de rotina, acidentes e escândalos'. In: TRAQUINA, Nelson (org.) Jornalismo: Questões, teorias, estórias. Lisboa Vega, pp. 34-51.

MOTTA, Luiz Gonzaga (2005). 'The opposition between mediacentric and sociocentric paradigms'. Brazilian Journalism Research, vol 1, $n^{\circ}$ 1, pp.61-86.

PORTO, Mauro P (2004). 'A TV e o primeiro turno das eleições presidenciais de 2002: A influência do Horário Eleitoral e do Jornal Nacional na decisão de voto'. Paper apresentado no IV Encontro Nacional da Associação Brasileira de Ciência Política. Rio de Janeiro.

(2002) Framing the world of politics: how governmental sources shape the production and the reception of TV news in Brazil, trabalho apresentado à XXIII Conferência Anual da International Association for Media and Communication Research (IAMCR), Barcelona. RIEFFEL, Rèmy (2005). Que sont les medias? Pratiques, identités, influences. Paris: Gallimard.
SAITTA, Eugénie (2004). 'L'Humanité, de l'organe de parti au journal communiste: 1999200. In: DELPORTE, Christian; PENNETIER, Claude; SIRINELLI, Jean-François et WILIKOW, Serge. L'Humanité de Jaurès à nous jours. Paris, Nouveau Monde Éditions, pp. 229-243.

SCHLENSIGER, Philip (1992). 'Repenser la sociologie du journalisme: Les estrategies de la source d'information et lês limites du médiacentrisme'. Reseaux, $n^{\circ}$ 51. Paris: Cenet, pp. 75-78

(1993) 'Os jornalistas e sua máquina do tempo'. In : TRAQUINA, Nelson (org.) Jornalismo: Questões, teorias, estórias. Lisboa (Portugal) Vega, pp.177-190.

SOUZA, Jorge Pedro (2000). As notícias e os seus efeitos. Coimbra, Portugal, Minerva. TRAQUINA, Nelson (2001). O Estudo do Jornalismo no Século XX. São Leopoldo: Ed. Unisinos.

Data do recebimento: 10/01/2006

Data do aceite: 15/03/2006 